\title{
A cinesiofobia e a preocupação com quedas estão associadas à redução da mobilidade funcional em pacientes com migrânea
}

\author{
Daiane Cristina Silva1 (D), Carina Ferreira Pinheiro' (D), Gabriela Ferreira Carvalho² (D), \\ Michely Rodrigues Rocha' ${ }^{1}$, Fabíola Dach ${ }^{1}$ (D) , Débora Bevilaqua-Grossi' ${ }^{1}$ (D)
}

'Faculdade de Medicina de Ribeirão Preto, Universidade de São Paulo, Ribeirão Preto, São Paulo, Brasil

2Universidade de Luebeck, Alemanha

\begin{abstract}
Introdução
Alterações de equilíbrio durante atividades funcionais tem sido observadas em pacientes com migrânea. A literatura sugere que as alterações de equilíbrio estático estão relacionadas com alterações vestibulares, presença de aura e migrânea crônica, porém não se sabe ainda se estes ou outros fatores estão associados à alterações no desempenho funcional dos migranosos.
\end{abstract}

\section{Objetivos}

Investigar a relação entre a mobilidade funcional e as características clínicas da migrânea, presença de sintomas vestibulares, diagnóstico de migrânea vestibular, ocorrência de quedas, medo de quedas e cinesiofobia.

\footnotetext{
Métodos

Participaram deste estudo transversal 79 mulheres com idade entre 18 a 55 anos, com diagnóstico de migrânea. As voluntárias responderam aos questionários Escala internacional de eficácia de quedas, Escala tampa de cinesiofobia e Dizziness Handicap Inventory, que avaliaram o medo de quedas, a cinesiofobia e a incapacidade relacionada aos sintomas vestibulares, respectivamente. A avaliação da mobilidade foi avaliada pelo teste Timed Up and Go (TUG). O estudo foi aprovado pelo comitê de ética em pesquisa (CAAE 04683218.3.0000.5440).
}

\section{Resultados}

A correlação entre as variáveis foi verificada com o Coeficiente de Correlação de Pearson, e modelos de regressão linear múltipla foram aplicados para verificar quais variáveis estavam associadas com a performance no TUG $(p<0.05)$. A mobilidade funcional apresentou correlação fraca e positiva com o medo de quedas $(r=0.37, p=0.001)$ e cinesiofobia ( $r=0.38, p=0.001)$. As demais variáveis não apresentaram correlação significativa com o TUG ( $p>0.05)$. A análise de regressão linear revelou que a cinesiofobia e o medo de quedas representam $17 \%$ da variabilidade do tempo de realização do teste Timed Up and Go.

\section{Conclusão}

A mobilidade funcional dos pacientes com migrânea está associada a cinesiofobia e ao medo de quedas, e pode ser influenciada em pequena proporção por estes mesmos fatores.

Palavras-chave: Transtornos migranosos, Quedas, Cinesiofobia, Equilíbrio postural, Migrânea vestibular. 